\title{
Effects of S-312, a New Calcium Antagonist, on the Mechanical and Electrophysiological Responses of Isolated Cardiovascular Preparations
}

\author{
Mitsuyoshi NINOMIYA, Tomoko TANI, Shigeyuki NAKAJIMA \\ and Motohiko UEDA \\ Shionogi Research Laboratories, Shionogi \& Co., Ltd.. \\ Fukushima-ku, Osaka 553, Japan \\ Accepted June 15. 1989
}

\begin{abstract}
S-312, a new calcium antagonist with a bicyclic dihydrothienopyridine structure, potently relaxed the helical strips of various isolated rabbit arteries precontracted with high $\mathrm{K}^{+}$-depolarization, serotonin (5-HT) and U46619 (thromboxane $\mathrm{A}_{2}$ analogue), and it competitively inhibited $\mathrm{Ca}^{++}$-induced contractions in depolarized basilar and femoral arteries. These effects of S-312 were more potent than nifedipine and almost comparable to or slightly more potent than those of nicardipine. In comparison with nifedipine and nicardipine, the calcium antagonistic effect and the relaxant effect on 5-HT-induced contractions of S-312 were most prominent in the basilar artery. The potent vasodilating action of S-312 in the high $\mathrm{K}^{+}$-depolarized basilar artery was not easily reversed by washing. S-312 did not affect $\mathrm{Ca}^{++}$-induced contraction in the skinned fiber of guinea pig taenia caecum. The negative inotropic effect of S-312 in isolated guinea pig left atria was much less potent than those of nifedipine and nicardipine. S-312 above $10^{-7} \mathrm{M}$ preferentially increased $A V$ nodal conduction time in Langendorff-perfused isolated rabbit hearts: and above $3 \times 10^{-8} \mathrm{M}$, it mainly decreased the maximum upstroke velocity of the action potential in isolated rabbit sinus node preparations. In summary, the present results indicate that $S-312$ is a potent new calcium antagonist possessing vasculoselectivity, especially for cerebral vessels.
\end{abstract}

Several dihydropyridine calcium antagonists including nifedipine have been widely used to treat various cardiovascular disorders such as hypertension, angina pectoris, myocardial infarction and cerebrovascular disorders (1. 2). Recently, several dihydropyridine derivatives have been developed which have a long lasting effect or relatively selective action in some vascular tissues. Nicardipine. which improves cerebrovascular circulation. has been clinically used in the treatment of various cerebrovascular disorders $(3,4)$. It has been recently shown that nimodipine selectively inhibits spasms of isolated cerebral arteries induced by spasmogenic agonists ( 5 . $6)$, and clinical evaluations are in progress for the treatment of ischemic complications in the brain $(7,8)$.
The calcium antagonistic effect of $\mathrm{S}-312$. methyl 4,7-dihydro-3-isobuthyl-6-methyl-4(3-nitrophenyl) thieno [2,3-b]pyridine-5-carboxylate (Fig. 1), was reported by Adachi et al. (9). Marked inhibitory effects of S-312 on specific $\left[{ }^{3} \mathrm{H}\right]$-nitrendipine (NTD) binding in rat cerebral cortex membranes, long lasting coronary dilation without any negative inotropic effect in the isolated guinea pig heart, and<smiles>COC(=O)C1=C(C)Nc2sccc2C1c1cccc([N+](=O)[O-])c1</smiles>

Fig. 1. Chemical structure of S-312. 
acute antihypertensive effect in conscious SHR by i.p. administration have been observed. These pharmacological effects of $S$ 312 indicated its potent and selective vasodilating property in comparison with its cardiac actions. However, the mode of action of S-312 on the vascular smooth muscle and cardiac muscle preparations has not been clarified yet.

In the present study, the mechanical and electrophysiological effects of S-312 on the isolated rabbit arteries, skinned fiber of guinea pig taenia caecum and cardiac preparations of rabbit or guinea pig were investigated. The mode of action and tissue specificity of S-312 were also evaluated and compared with those of nifedipine and nicardipine.

\section{Materials and Methods}

\section{Preparation of rabbit arterial strips and} tension measurement

Adult male Japanese white rabbits, weighing $1.9-2.7 \mathrm{~kg}$, were stunned on the head and exsanguinated. Femoral arteries and proximal portions of the mesenteric arteries were quickly dissected. The right coronary artery and circumflex branch of the left coronary artery, basilar artery and interlobar branches of the renal artery were carefully isolated from the heart, brain and kidneys, respectively. After removal of connective tissue, isolated arteries were helically cut into strips $(1-2 \mathrm{~cm}$ long). The strip was mounted in a $20-\mathrm{ml}$ muscle bath filled with Krebs-Henseleit solution $\left(37^{\circ} \mathrm{C}\right)$ which was aerated with a mixture of $95 \% \mathrm{O}_{2}$ and $5 \% \mathrm{CO}_{2}$. The lower end of a strip was attached to a stainless steel rod, and the upper end was connected to a force transducer (Nihon Kohden) for isometric tension measurement. The resting tension was adjusted to $0.5 \mathrm{~g}$. The composition of the solution was as follows: $130.9 \mathrm{mM} \mathrm{NaCl}, 5.9$ $\mathrm{mM} \mathrm{KCl}, 2.5 \mathrm{mM} \mathrm{CaCl}_{2}, 11.9 \mathrm{mM} \mathrm{NaHCO}_{3}$. $1.2 \mathrm{mM} \mathrm{NaH}_{2} \mathrm{PO}_{4}, 1.2 \mathrm{mM} \mathrm{MgSO}_{4}$ and 11.0 $\mathrm{mM}$ glucose ( $\mathrm{pH} 7.3$ ). Before the start of each experiment, the strips were allowed to equilibrate in the muscle bath for 60-90 min and then contracted repeatedly with $50 \mathrm{mM} \mathrm{K}^{+}$to obtain constant responses.

\section{Effect on isolated rabbit arteries}

2.1. Calcium antagonistic effect in depolarized rabbit arteries: Isolated femoral and basilar arterial strips were washed with $\mathrm{Ca}^{++}$free, $\mathrm{K}^{+}(50 \mathrm{mM})$-depolarizing solution, in which the $\mathrm{NaCl}$ concentration was reduced to $80.9 \mathrm{mM}$ and $\mathrm{NaH}_{2} \mathrm{PO}_{4}$ was not used to avoid precipitation of $\mathrm{Ca}$-salts. This treatment produced a transient contraction, which vanished completely by washing four times with $\mathrm{Ca}^{++}$-free, $\mathrm{K}^{+}$-depolarizing solution. After $65 \mathrm{~min}$ exposure to $\mathrm{Ca}^{++}$-free, $\mathrm{K}^{+}$depolarizing solution, the cumulative doseresponse curve for $\mathrm{Ca}^{++}$was determined. This set of experiments was performed three times. Between each set of experiments, the strips were washed with normal solution for $30 \mathrm{~min}$. No significant difference was observed between the second and third dose-response curves for $\mathrm{Ca}^{++}$. In the second set of experiments, the control dose-response curve for $\mathrm{Ca}^{++}$was determined, and calcium antagonist was added $45 \mathrm{~min}$ before the third doseresponse curve.

2.2. Effects on high $\mathrm{K}^{+},-5-\mathrm{HT}$ - and U46619-induced contractions of rabbit arteries: In order to evaluate the relaxant activity, S-312, nifedipine or nicardipine was added cumulatively to the muscle bath during sustained contraction of various arteries induced by high $\mathrm{K}^{+}(50 \mathrm{mM}), 5-\mathrm{HT}\left(3 \times 10^{-6}\right.$ $\left.2 \times 10^{-5} \mathrm{M}\right)$ or $\mathrm{U} 46619\left(10^{-8} \mathrm{M}\right)$. At the end of each series of experiments, papaverine $\left(10^{-4} \mathrm{M}\right)$ was applied to produce the maximum relaxation (10)

2.3. Effect on NE-induced contraction of rabbit femoral artery: Cumulative administration of NE was repeated to obtain steady dose-response curves for NE. Then the effect of pretreatment of the calcium antagonist for 60 min on the NE dose-response curve was examined.

2.4. Effect on $\mathrm{Ca}^{++}$-induced contraction of $\mathrm{NE}$-exposed rabbit femoral artery: Isolated femoral arterial strips were washed with $\mathrm{Ca}^{++}$free solution containing $0.1 \mathrm{mM}$ EGTA for 20 min and then exposed to $3 \times 10^{-6} \mathrm{MNE}$. These procedures were repeated four times. NEinduced contraction in $\mathrm{Ca}^{++}$-free solution vanished almost completely with these four repetitions. Dose-response curves for $\mathrm{Ca}^{++}$in the presence of NE were then determined in drug-treated (60 $\mathrm{min}$ ) and non-treated strips which were prepared from the same animal.

2.5. Duration of vasodilating activity of 
calcium antagonist: Isolated rabbit basilar arterial strips were contracted with high $\mathrm{K}^{+}$ $(50 \mathrm{mM})$ and relaxed with calcium antagonist. When the strips relaxed to reach a new steady level, they were washed out with drug-free high $\mathrm{K}^{+}$solution and allowed to recover the contraction. In these experiments, we examined the effects of the calcium antagonist at two different concentrations which induced half maximum and submaximum relaxation in the high $\mathrm{K}^{+}$-depolarized basilar artery.

3. Effect on the contraction of isolated skinned guinea pig taenia caecum

A strip of taenia caecum, $0.05-0.1 \mathrm{~mm}$ wide and $2-3 \mathrm{~mm}$ long. was freshly isolated from male guinea pigs weighing $500-700 \mathrm{~g}$. Preparations were mounted in a small chamber filled with relaxing solution containing 130 $\mathrm{mM}$ K-propionate, $20 \mathrm{mM}$ Tris-malete, $4 \mathrm{mM}$ $\mathrm{MgCl}_{2}, 4 \mathrm{mM} \mathrm{ATP}$ and $2 \mathrm{mM} \mathrm{EGTA}$, and then aerated with $100 \% \mathrm{O}_{2}$ at $20^{\circ} \mathrm{C}(\mathrm{pH} \mathrm{6.8)}$. The preparations were treated with $50-100 \mu \mathrm{g} / \mathrm{ml}$ saponin for 20-30 min. The relaxant effect of the drugs was examined in the strips which were partially precontracted with $10^{-6} \mathrm{M}$ $\mathrm{Ca}^{++}$solution containing $2 \mathrm{mM}$ EGTA. The apparant binding constant of EGTA for $\mathrm{Ca}^{++}$ at $20^{\circ} \mathrm{C}, \mathrm{pH} 6.8$, was considered to be $10^{6}$ $\mathrm{M}^{-1}(11)$.

\section{Effect on the isolated guinea pig or rabbit cardiac preparations}

4.1. Inotropic effect in guinea pig left atria: Left atria were isolated from guinea pigs and suspended in a $20-\mathrm{ml}$ muscle bath filled with Krebs-Ringer solution $\left(30^{\circ} \mathrm{C}\right)$ which was aerated with a mixture of $95 \% \mathrm{O}_{2}$ and $5 \% \mathrm{CO}_{2}$. The composition of the Krebs-Ringer solution was as follows: $120.3 \mathrm{mM} \mathrm{NaCl}, 4.0 \mathrm{mM} \mathrm{KCl}$, $1.2 \mathrm{mM} \mathrm{CaCl}_{2}, 1.3 \mathrm{mM} \mathrm{MgSO}_{4}, 1.2 \mathrm{mM}$ $\mathrm{NaH}_{2} \mathrm{PO}_{4}, 25.2 \mathrm{mM} \mathrm{NaHCO}$ and $5.8 \mathrm{mM}$ glucose ( $\mathrm{pH} 7.4$ ). Resting tension was adjusted to $0.2 \mathrm{~g}$. Electrical stimulation was applied with a pair of bipolar silver electrodes by rectangular pulses of $0.5 \mathrm{msec}$ duration at twice the threshold intensity and with a frequency of $1.0 \mathrm{~Hz}$. The developed tension was recorded by procedures similar to those described in section 1. Under these conditions, the preparation was treated with a single concentration of drug for $60 \mathrm{~min}$.

4.2. Dromotropic effect in Langendorffperfused rabbit heart: The solated rabbit heart was perfused with Krebs-Ringer solution $\left(32 \pm 1{ }^{\circ} \mathrm{C}\right)$ equilibrated with $95 \% \mathrm{O}_{2}$ and $5 \%$ $\mathrm{CO}_{2}$ at a constant perfusion rate of about 10 $\mathrm{ml} / \mathrm{min}$. The His bundle electrogram was recorded by bipolar silver wires placed on the area of the His bundle. The preparation was stimulated with a pair of bipolar silver electrodes on the pacemaker area of the right atrium under the following conditions: a basic stimulus interval, about $480 \mathrm{msec}$ : intensity. $2 x$ threshold; duration. $2 \mathrm{msec}$.

Atrial conduction time (SA), atrioventricular nodal conduction time $(A H)$ and HisPurkinje conduction time (HV) were measured with the His bundle electrogram: SA interval, from the stimulus artifact to the earliest onset of atrial excitation ( $A$ wave); AH interval, from the A wave to the His signal; $H V$ interval, from the His signal to the earliest onset of ventricular excitation.

4.3. Electrophysiological effects in rabbit sinus node preparations: A sinus node specimen $(2 \times 2 \mathrm{~mm})$ was cut perpendicular to the crista terminalis of rabbit heart. The preparation of the sinus node was superfused continuously with Krebs-Ringer solution saturated with $95 \% \mathrm{O}_{2}$ and $5 \% \mathrm{CO}_{2}$ at $33^{\circ} \mathrm{C}$. Transmembrane action potentials of the isolated sinus node preparations were recorded using standard glass microelectrodes filled with $3 \mathrm{M} \mathrm{KCl}$. The maximum upstroke velocity of the action potential $\left(\dot{\mathrm{V}}_{\max }\right)$ was obtained by electronic differentiation. The records of the transmembrane potential and $\dot{V}_{\max }$ were displayed on a Tektronic 5113 dual beam storage oscilloscope.

\section{Data analysis and drugs}

Experimental results are expressed as the mean \pm S.E. Statistical analysis were performed using Tukey's method after one-way analysis of variance (12) and Student's $t$ test. Drugs employed in these experiments were S-312 (Shionogi), nifedipine (Teikoku Kagaku), nicardipine (Yamanouchi), saponin $(\mid C N)$, trifluoperazine (Sigma), serotonin creatinine sulfate (Merck), U46619 (Cayman Chemi). ( \pm )-norepinephrine hydrochloride, and papaverine hydrochloride. S-312, nifedipine and nicardipine were dissolved in $90 \%$ dimethylsulfoxide (DMSO) and $10 \%$ castor oil ( $\mathrm{HCO}-50)$ and diluted with distilled water before use. Nifedipine solution was prepared 
just before its application. To examine the calcium antagonistic effects of nifedipine in the isolated arteries, experiments were performed under a sodium-light in a dark room. Other experiments with nifedipine were done under indoor-lighting: however, the muscle bath was covered by aluminum foil or black tape to protect the drug from degradation by light.

\section{Results}

\section{Effect on isolated rabbit arteries}

1.1. Calcium antagonistic effect in depolarized rabbit arteries: S-312 showed competitive antagonism against $\mathrm{Ca}^{++}$-induced contraction, producing a rightward displacement of the dose-response curve for $\mathrm{Ca}^{++}$in rabbit femoral and basilar arteries (Fig. 2). Parallelism between control and dose-response curves with $S-312$ was indicated by parametric parallel line testing (13). Similar results were obtained with nifedipine and nicardipine (Fig. 2). $\mathrm{pA}_{2}$ values of S-312, nifedipine and nicardipine were determined by Schild plots (14). The Schild plot for these calcium antagonists gave a regression line with a slope of 1.03-1.21 and a correlation coefficient above 0.991 (Fig. 3). The $\mathrm{pA}_{2}$ values of S-312, nifedipine and nicardipine in the femora! artery were 10.045, 9.343 and 10.310, respectively. The values in the basilar artery were $10.420,9.455$ and 10.303 , respectively. The calcium antagonistic effect of S-312 in the basilar artery was clearly more potent than that the femoral artery. However. such a significant difference in the potencies between the two arteries was not clear with nifedipine and nicardipine. In the isolated basilar artery, the calcium antagonistic effect of $\mathrm{S}-312$ is approximately 9.2 or 1.3 times more potent than that of nifedipine or nicardipine, respectively.

1.2. Effects on high $\mathrm{K}^{+}-, 5-\mathrm{HT}$ - and U46619-induced contractions of rabbit arteries: Sustained contractions in strips of basilar, coronary, mesenteric. renal and femoral arteries with $50 \mathrm{mM} \mathrm{K}^{+}$were dosedependently relaxed by the cumulative addition of $\mathrm{S}-312$ at concentrations ranging from $3 \times 10^{-11}$ to $10^{-8} \mathrm{M}$ (Fig. 4). These ar-

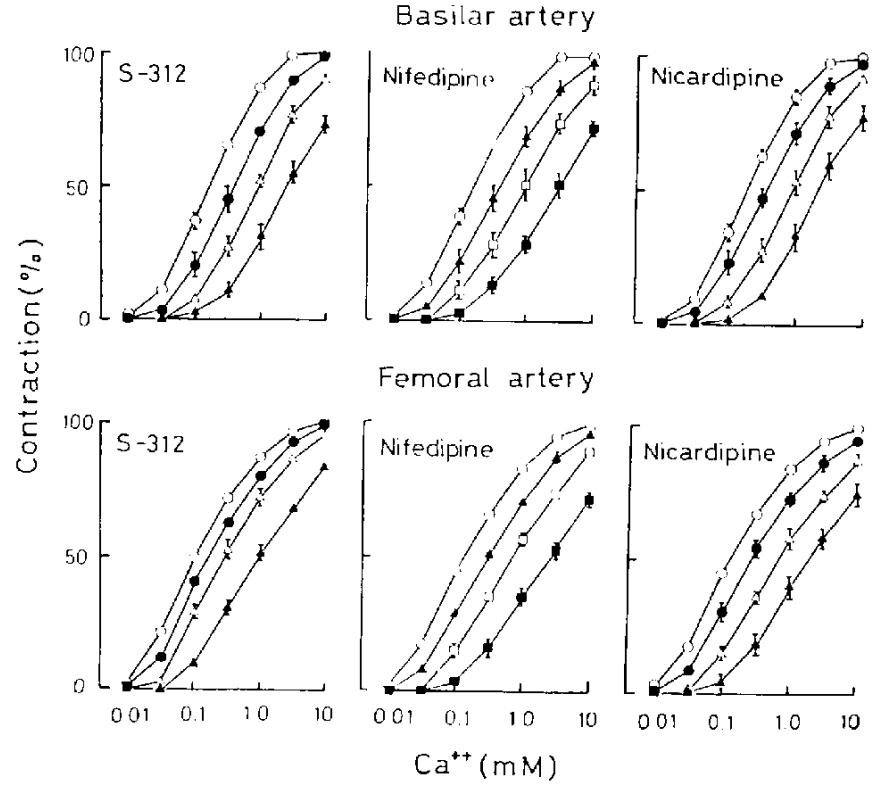

Fig. 2. Effects of $\mathrm{S}-312$, nifedipine and nicardipine on concentration-response curves for $\mathrm{Ca}^{++}$in the isolated rabbit basilar and femoral arteries. Each point represents the mean \pm S.E. of $15-16$ preparations in control curves $(O)$ and 5-6 preparations in curves with calcium antagonists. The concentrations of calcium antagonists were $5 \times 10^{-11} \mathrm{M}(\mathbf{O}) .1 .5 \times 10^{-10} \mathrm{M}(\triangle) .5 \times 10^{-10}(\boldsymbol{\Lambda}), 1.5 \times 10^{-9} \mathrm{M}([\mathrm{C})$ and $5 \times 10^{-9} \mathrm{M}(\square)$. The maximal contraction in the control curve was taken as $100 \%$. 


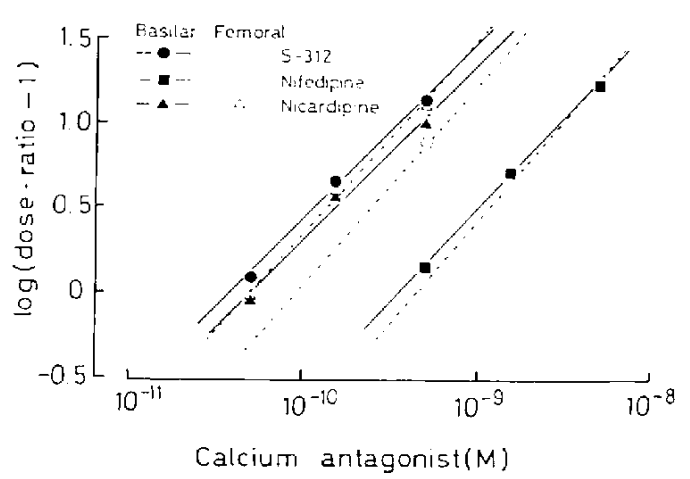

Fig. 3. The Schild plot for S-312, nifedipine and nicardipine antagonism on the $\mathrm{Ca}^{++}$-induced contraction in rabbit basilar and femoral arteries. Regression lines were fitted by the method of least squares. The $\mathrm{pA}_{2}$ values and slope for the antagonism by calcium antagonists were given in the Results.

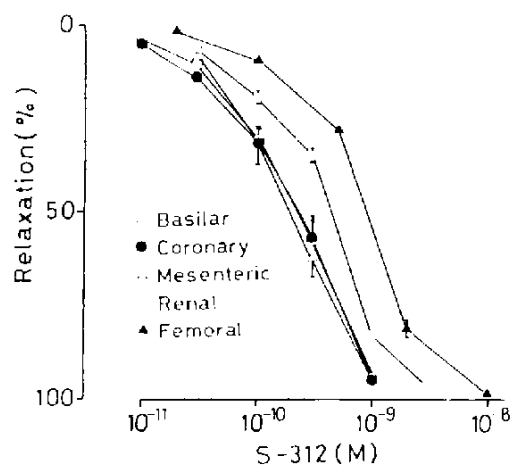

Fig. 4. Concentration-relaxation curves for $\mathrm{S}-312$ in the isolated rabbit basilar, coronary, mesenteric. renal and femoral arterial strips precontracted with $50 \mathrm{mM} \mathrm{K} \div$ depolarization. Relaxation induced by $10^{-4}$ $M$ papaverine was taken as $100 \%$. Mean develaped tensions with \pm S.E. (mg) in basilar, coronary. mesenteric, renal and femoral arteries induced with $50 \mathrm{mM} \mathrm{K} \mathrm{K}^{+}$were $483 \pm 74 \quad(n=5), 493 \pm 75 \quad(n=7)$. $202 \pm 23(n=5), 1343 \pm 190 \quad(n=5)$ and $2510 \pm 90$ $(n=6)$, respectively.

terial strips were relaxed with $\mathrm{S}-312$ almost completely at $10^{-9} \mathrm{M}$ to $10^{-8} \mathrm{M}$.

$\mathrm{S}-312$ also relaxed the strips of basilar. coronary, mesenteric and femoral arteries precontracted with 5-HT in a dose-related manner (Fig. 5). In the strips of basilar. coronary and mesenteric arteries, almost complete relaxations were observed at $10^{-7} \mathrm{M}$. while the relaxations were incomplete in the

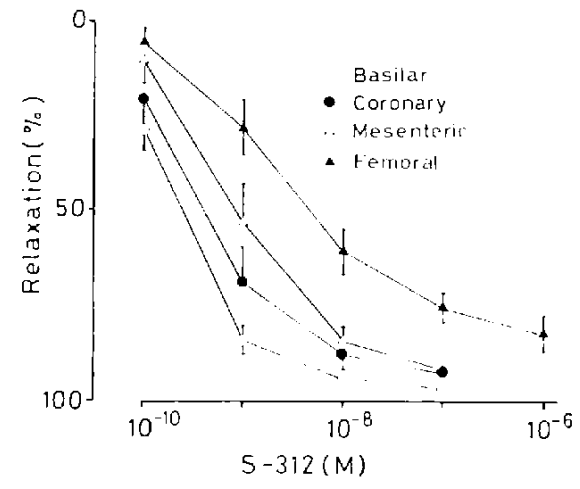

Fig. 5. Concentration-relaxation curves for S-312 in rabbit basilar, coronary, mesenteric and femoral arterial strips precontracted with $3 \times 10^{-6}$ to $2 \times 10^{-5}$ M 5-HT. Relaxation induced by $10^{-4} \mathrm{M}$ papaverine was taken as $100 \%$. Mean developed tensions with \pm S.E. ( $m g, n=5)$ in basilar. coronary. mesenteric and femoral arteries induced with 5 - HT were $382 \pm 75,431 \pm 109.223 \pm 34$ and $730 \pm 53$, respectively.

femoral artery even at the highest concentration tested $\left(10^{-6} \mathrm{M}\right)$. Similar relaxations were observed for nifedipine and nicardipine in strips precontracted with high $\mathrm{K}^{+}$or $5-\mathrm{HT}$.

ED50 values of these relaxant effects for each drug are given in Table 1. Here, the ED50 values were obtained by fitting the doseresponse curves to 4 -parameter logistic curves (15). As seen in the Table, these relaxant effects of S-312 on the high $\mathrm{K}^{+}$- and $5-\mathrm{HT}$ induced contractions were more potent than those of nifedipine, and they were almost comparable to those of nicardipine. The relaxant effect of S-312 on high $\mathrm{K}^{+}$-induced contraction was more pronounced in mesenteric, basilar and coronary arteries than those in the other arteries. The relaxant effect of S312 on $5-H T$-induced contraction was most prominent in the basilar artery, and its potencies decreased in the order of basilar $>$ coronary $>$ mesenteric $>$ femoral arteries. Such a selective action of S-312 on the basilar artery was remarkable compared with nifedipine and nicardipine. Relaxant effects of nifedipine and nicardipine were more prominent in the coronary artery than in the basilar artery

In isolated rabbit coronary arterial strips. sustained contractions were induced by $10^{-8}$ 
Table 1. Negative logarithm of ED50 values of calcium antagonists for high $\mathrm{K}^{+}, 5-\mathrm{HT}$ and U46619induced contraction in isolated rabbit arteries

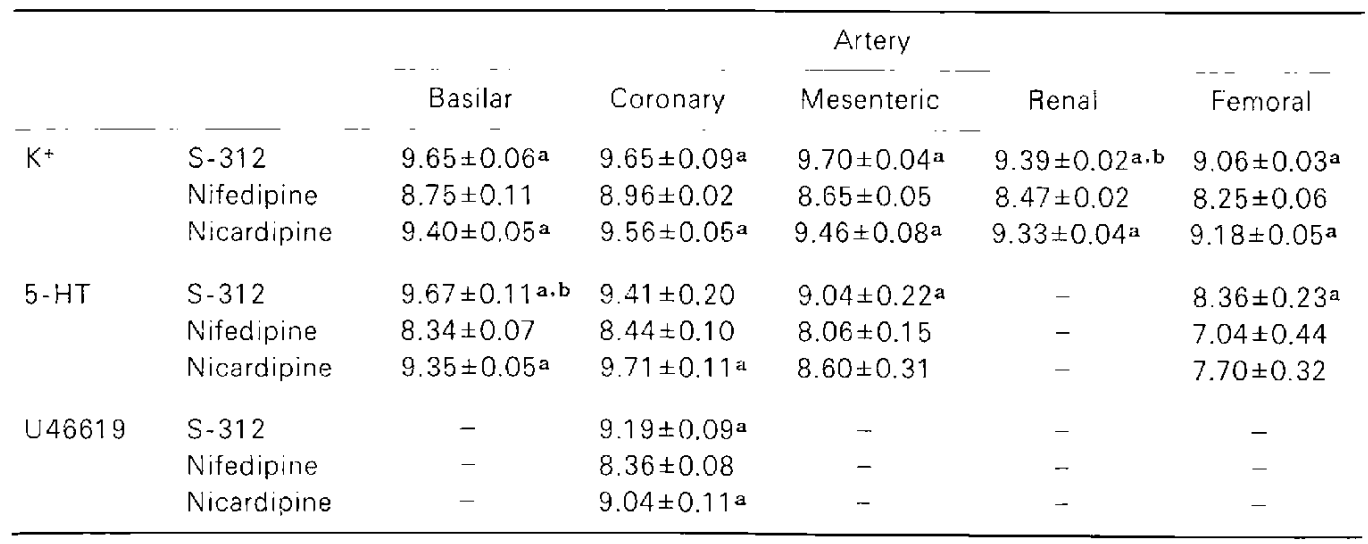

Values are means \pm S.E. of five to seven preparations. a bsignificantly different from the nifedipine or nicardipine group at $P \propto 0.05$, respectively (Tukey's Method).

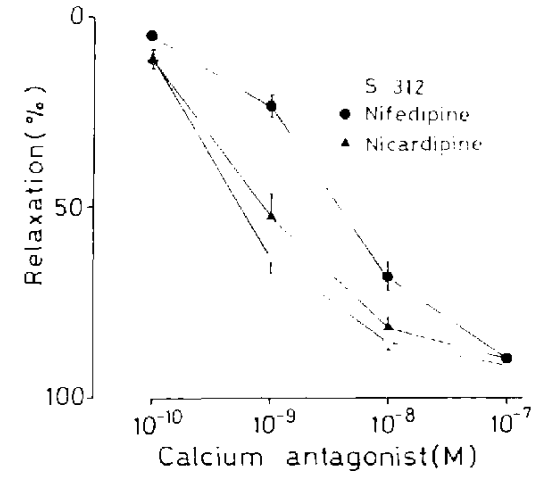

Fig. 6. Comparison of relaxant effects of S-312. nifedipine and nicardipine in rabbit coronary arterial strips precontracted with $10^{-8}$ U46619. Each point represents the mean $\pm S$.E. of five preparations. Relaxation induced by $10^{-4} \mathrm{M}$ papaverine was taken as 100\%. Mean developed tension induced with U 46619 was $435 \pm 29 \mathrm{mg}(\mathrm{n}=15)$.

$M \cup 46619$, a stable thromboxane $A_{2}$ analogue $(16,17)$. S-312, nifedipine and nicardipine produced relaxation in coronary arterial strips precontracted with $\cup 46619$ in a doserelated manner (Fig. 6), and the ED50 values of these relaxant effects are shown in Table 1. The relaxant effect of $\mathrm{S}-312$ was more potent than that of nifedipine and slightly more potent than that of nicardipine.

No significant differences in the upper and lower limits were observed between calcium antagonists in the logistic curves, to which the dose-response curves for calcium antagonist-induced relaxant effects on high $\mathrm{K}^{+}$5 -HT- and U46619-induced contractions were fitted. However, some significant differences in the slopes, of the logistic curves were observed as follows (mean \pm S.E.): $\mathrm{K}^{+}$-induced contraction (coronary), nicardipine $(3.41 \pm 0.04)>$ nifedipine $(2.53 \pm 0.06)$ and $\mathrm{S}-312(2.08 \pm 0.19): \mathrm{K}^{+}$-induced contraction (renal), nifedipine $(1.82 \pm 0.01)<\mathrm{S}-312$ $(2.86 \pm 0.24)$ and nicardipine $(3.10 \pm 0.19) ; 5$ HT-induced contraction (coronary), S-312 $(2.86 \pm 0.33)>$ nifedipine $(1.61 \pm 0.11)$ and nicardipine $(1.78 \pm 0.08) ; \quad U 46619$-induced contraction, $\mathrm{S}-312(2.74 \pm 0.17)>$ nifedipine (1.82 \pm 0.19$)$ and nicardipine (2.40 0.18$)$.

1.3. Effect on NE-induced contraction of rabbit femoral artery: $\mathrm{S}-312$ shifted the NE dose-response curve in rabbit femoral artery not only to the right, but also depressed the maximal response (Fig. 7). A similar mode of action was observed for nifedipine and nicardipine. S-312, nifedipine and nicardipine thus inhibited the NE contraction in a non-competitive manner. However, these three drugs only partially inhibited the NE-induced contraction even at the higher concentration $\left(10^{-6} \mathrm{M}\right)$ tested. The mean \% decrease $(n=5)$ in the maximal NE-response caused by $10^{-7}$ $M$ of each calcium antagonist was as follows: S-312, 23.6: nifedipine, 13.7; nicardipine. 21.7 

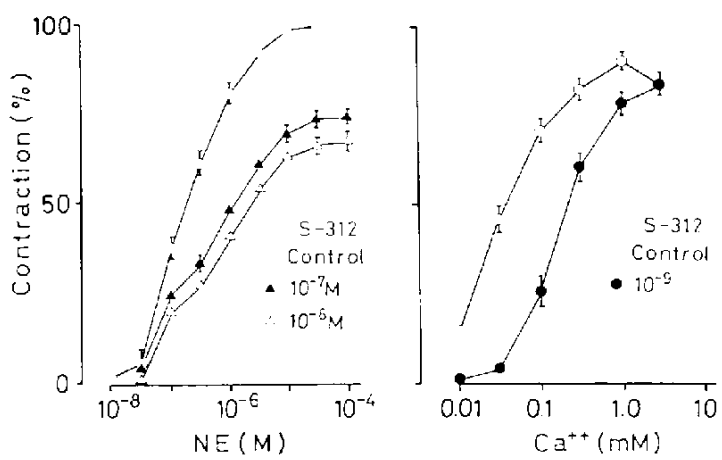

Fig. 7. Effects of S-312 on NE-induced contraction (left panel) and $\mathrm{Ca}^{++}$-induced contraction of NEexposed strips (right panel) in rabbit femoral artery. Maximal contraction induced by NE determined in the same strip exposed to normal solution was taken as $100 \%$ in each graph. Mean maximal developed tension induced by NE was $3.04 \pm 0.14 \mathrm{~g}(n=15)$.

1.4. Effect on NE-induced contraction in $\mathrm{Ca}^{++}$-free solution of rabbit femoral artery: When NE was added repeatedly every 20 min under the $\mathrm{Ca}^{++}$-free condition, $\mathrm{NE}$-induced contraction decreased gradually. The mean contractions of the first, second, third and fourth NE-induced response were 58, 18, 3.0 and $1.8 \%$, respectively, when the response in normal solution is taken as $100 \%$. These contractions obtained in $\mathrm{Ca}^{++}$-free solution were not affected by the addition of $10^{-9} \mathrm{M} \mathrm{S-312}$ to the muscle bath.

1.5. Effect on $\mathrm{Ca}^{++}$-induced contraction of $\mathrm{NE}$-exposed rabbit femoral artery: $\mathrm{Ca}^{++}$ induced contractions of NE-exposed femoral arterial strips (Fig. 7) were observed at a lower concentration of $\mathrm{Ca}^{++}$than those of $\mathrm{K}^{+}$depolarized femoral arterial strips (Fig. 2). Similar high sensitivity to $\mathrm{Ca}^{++}$has been reported for NE-exposed rat resistance vessels (18). S-312 inhibited this $\mathrm{Ca}^{++}$-induced contraction even at a low concentration $\left(10^{-9} \mathrm{M}\right)$. producing a rightward parallel shift of the dose-response curve (Fig. 7). Parallelism between the control and dose-response curves with S-312 was indicated by parametric parallel line testing (13). Nifedipine and nicardipine also showed similar antagonism. The $\mathrm{pA}_{2}$ values for S-312, nifedipine and nicardipine. which were determined by the method of van Rossum (19), were as follows $(m e a n \pm$ S.E., $n=5)$ : S-312. $9.71 \pm 0.03$; nife-
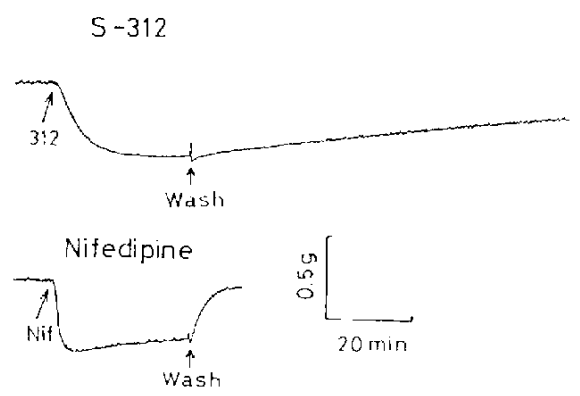

Fig. 8. Typical recordings of the relaxant response to S-312 and nifedipine, and of recontraction following drug removal from the isolated rabbit basilar arterial strip. The strip was precontracted with $50 \mathrm{mM} \mathrm{K}$ * and relaxed with a submaximal concentration of $S$ $312\left(10^{-9} \mathrm{M}\right)$ or nifedipine $\left(5 \times 10^{-9} \mathrm{M}\right)$, and then washed out with drug-free $50 \mathrm{mM} \mathrm{K} \mathrm{K}^{+}$solution.

dipine, $8.62 \pm 0.06$; nicardipine, $9.49 \pm 0.04$.

1.6. Duration of vasodilating activity of calcium antagonist: In the drug-free high $\mathrm{K}^{+}$ solution, isolated rabbit basilar artery which had been relaxed with $S-312$ or nifedipine recontracted gradually almost to the initial level (Fig. 8). The time required for $50 \%$ recontraction was calculated as the index of the duration of the vasodilating action of the calcium antagonist (Table 2). The duration of vasodilating action caused by a high concentration of S-312 was significantly longer than that induced by a low concentration of S-312. Similar dose-dependency on the duration of the vasodilating action has been reported previously with nilvadipine (20). Both in high and low concentrations, S-312 caused more prolonged vasodilating action than those caused by nifedipine and nicardipine. The differences in the duration of the vasodilating action was considerable compared with that in the speed of relaxation. which was evaluated from the time required for $50 \%$ relaxation (Table 2).

2. Effects on contraction of isolated skinned guinea pig taenia caecum

in skinned muscle fibers of guinea pig taenia caecum, the contractile tensions produced with $10^{-4}$ or $10^{-5} \mathrm{M} \mathrm{Ca}^{++}$almost corresponded to that with $140 \mathrm{mM} \mathrm{K}^{+}$in intact muscles. After the contraction evoked by $10^{-6}$ $\mathrm{M} \mathrm{Ca}^{++}$had reached a steady level, the effect of $\mathrm{S}-312$ at $10^{-8}$ or $10^{-4} \mathrm{M}$ was observed. 
Table 2. Times required for $50 \%$ relaxation and recontraction following addition and removal of calcium antagonist in depolarized $\left(50 \mathrm{mM} \mathrm{K}^{+}\right)$rabbit basilar artery

\begin{tabular}{lccc}
\hline \multirow{2}{*}{ Drug } & Conc. $(M)$ & \multicolumn{2}{c}{ Time (min) } \\
\cline { 2 - 3 } & & Relaxation & Recontraction \\
S-312 & $2 \times 10^{-10}$ & $6.8 \pm 0.8$ & $29.7 \pm 9.3$ \\
& $10^{-9}$ & $5.4 \pm 1.0$ & $93.3 \pm 16.2$ \\
Nifedipine & $10^{-9}$ & $2.0 \pm 0.2$ & $2.1 \pm 0.2$ \\
& $5 \times 10^{-9}$ & $1.2 \pm 0.1$ & $2.7 \pm 0.4$ \\
Nicardipine & $2 \times 10^{-10}$ & $5.7 \pm 0.4$ & $8.3 \pm 0.9$ \\
\hline
\end{tabular}

Values are means $\pm S . E . \quad(n=5)$

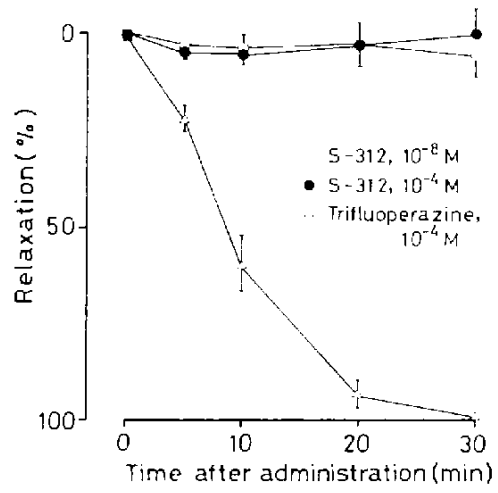

Fig. 9. Effects of $\mathrm{S}-312$ and trifluoperazine on skinned fibers of guinea pig taenia caecum precontracted with $\mathrm{Ca}^{++}$at $10^{-6} \mathrm{M}$. The degree of the relaxant effect is shown as the percentage of the contraction induced by $10^{-6} \mathrm{M} \mathrm{Ca}^{++}$, with the meant S.E. of five experiments.

Figure 9 shows the time course of contractile tension obtained after applications of S-312. S-312 did not affect the contraction evoked by $10^{-6} \mathrm{M} \mathrm{Ca}^{++}$, while $10^{-4} \mathrm{M}$ trifluoperazine, a calmodulin inhibitor $(21,22)$, caused marked relaxation (Fig. 9). These results indicate that the calcium receptors of contractile protein were not affected by $S-312$

3. Effects on isolated guinea pig or rabbit cardiac preparations

3.1. Inotropic effect in guinea pig left atria: The electrically driven contraction of the left atrium was dose-dependently inhibited by $S$ 312 at concentrations ranging from $3 \times 10^{-7}$ to $3 \times 10^{-5} \mathrm{M}$ (Fig. 10). These inhibitory concentrations were much higher than those required

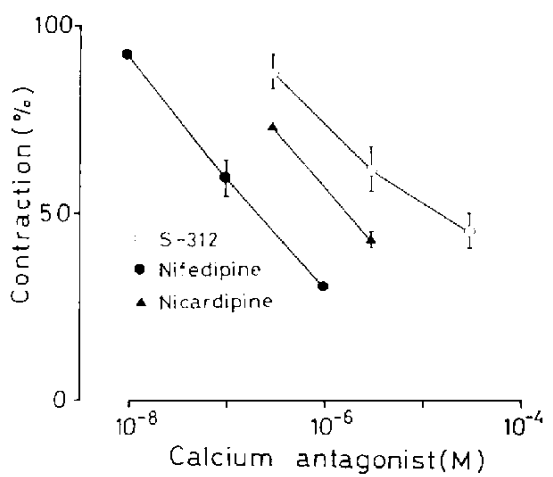

Fig. 10. Negative inotropic effects of $\mathrm{S}-312$, nifedipine and nicardipine in isolated guinea pig left atria which were electrically driven. Symbols represent the mean $\pm S$.E. of four separate experiments. Mean developed tension induced by electrical stimulation was $435 \pm 27 \mathrm{mg}(n=32)$. The ED50 values with $95 \%$ confidence limits for S-312, nifedipine and nicardipine were $1.54 \quad(0.70$ $5.88) \times 10^{-5} \mathrm{M}, 2.22(1.65-3.08) \times 10^{-7} \mathrm{M}$ and 1.74 $(1.30-2.23) \times 10^{-6} \mathrm{M}$, respectively.

for calcium antagonistic and relaxant effects in the arterial preparations mentioned before. Nifedipine and nicardipine also showed similar negative inotropic effects, but their inhibitory potencies were significantly greater than that of S-312 (Fig. 10).

3.2. Dromotropic effects in Langendorffperfused rabbit heart: Figure 11 shows the percentage changes of the $\mathrm{SA}, \mathrm{AH}$ and $\mathrm{HV}$ intervals after 30-min exposure to S-312. S312 above $10^{-7} \mathrm{M}$ produced a dose-dependent increase in the $\mathrm{AH}$ interval, but did not affect the SA and HV intervals even at the 
highest concentration $\left(3 \times 10^{-7} \mathrm{M}\right)$ tested. These results indicated that S-312 preferentially delayed the conduction through the atrioventricular node.

3.3. Electrophysiological effects in rabbit sinus node preparations: Each impalement of the microelectrode in the preparation yielded a typical pacemaker potential with a smooth rising phase as reported previously (23). The action potential records obtained before and 30 min after application of S-312 are shown in Fig. 12, and changes in the various parameters of the action potentials are summarized in Table 3.

Although no effect was observed in any

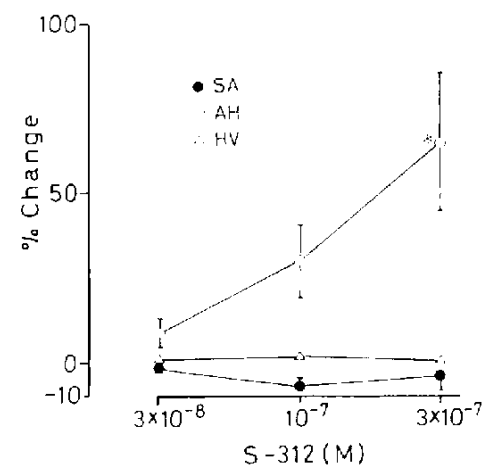

Fig. 11. Effects of S-312 on SA. AH and HV intervals of $H$ is bundle electrogram in the Langendorffperfused isolated rabbit heart. Mean control values with \pm S.E. of SA, A.H and HV intervals (msec, $n=5$ ) were $21.4 \pm 2.4,44.4 \pm 3.9$ and $36.5 \pm 3.2$, respectively. * Significantly different from the initial value at $P<$ 0.05 . action potential parameters at $10^{-8} \mathrm{M}, \mathrm{S}-312$ above $3 \times 10^{-8} \mathrm{M}$ caused decreases in $\dot{\mathrm{V}}_{\mathrm{msx}}$ and the action potential amplitude (AMP) in a dose-related manner, and significant changes were observed above $10^{-7} \mathrm{M}$ of S-312. S312 also significantly decreased the maximum diastolic potential (MDP) at $3 \times 10^{-7} \mathrm{M}$, and tended to decrease the action potential duration at $50 \%$ repolarization $\left(A P D_{50}\right)$ and increased the spontaneous cycle length ( $\mathrm{SCL}$ ).

A

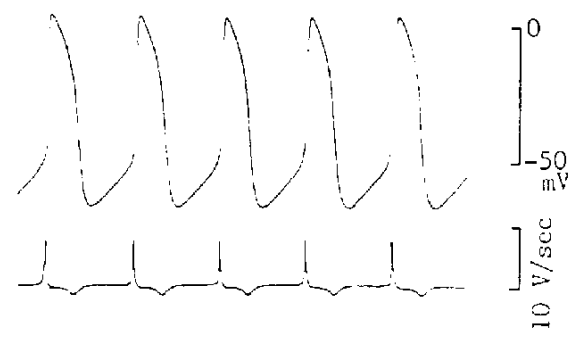

B

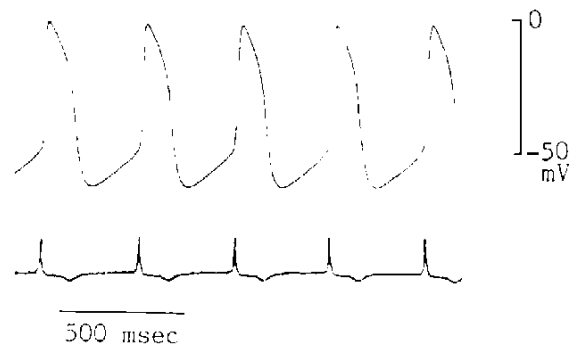

Fig. 12. Effects of S-312 on the transmembrane action potential of spontaneously beating rabbit sinus node preparations. The upper and lower tracing in each section show the membrane action potential and its differentiated upstroke spike. A: control. B: $10^{-7} \mathrm{M}$ of $\mathrm{S}-312$.

Table 3. Effects of $\mathrm{S}-312$ on the transmembrane action potential of isolated rabbit sinus node preparations

\begin{tabular}{|c|c|c|c|c|c|}
\hline \multirow{2}{*}{ Parameter } & \multirow{2}{*}{ Control } & \multicolumn{4}{|c|}{$\mathrm{S}-312(\mathrm{M})$} \\
\hline & & $10^{-8}$ & $3 \times 10^{-8}$ & $10^{-7}$ & $3 \times 10^{-7}$ \\
\hline $\operatorname{AMP}(m V)$ & $75.1 \pm 2.6$ & $73.3 \pm 3.5$ & $68.0 \pm 3.6$ & $58.0 \pm 3.2^{*}$ & $45.2 \pm 3.8^{*}$ \\
\hline $\operatorname{MDP}(\mathrm{mV})$ & $70.2 \pm 2.7$ & $69.4 \pm 3.4$ & $69.1 \pm 2.2$ & $64.0 \pm 1.0$ & $54.8 \pm 4.9^{*}$ \\
\hline$\dot{V}_{\max }(V /$ sec $)$ & $8.84 \pm 0.88$ & $8.89 \pm 1.13$ & $6.65 \pm 0.58$ & $4.94 \pm 0.36^{*}$ & $3.73 \pm 1.14^{*}$ \\
\hline$A P D_{50}(m s e c)$ & $94.9 \pm 5.7$ & $92.9 \pm 6.2$ & $92.2 \pm 7.1$ & $86.2 \pm 7.3$ & $82.2 \pm 9.2$ \\
\hline SCL (msec) & $359 \pm 10$ & $374 \pm 8$ & $383 \pm 13$ & $404 \pm 28$ & $399 \pm 40$ \\
\hline
\end{tabular}

Values are means \pm S.E. $(n=5)$. Abbreviations: AMP, action potential amplitude: MDP, maximum diastolic potential: $\dot{V}_{\max }$ maximum upstroke velocity: $\mathrm{APD}_{50}$, action potential duration at $50 \%$ repolarization: SCL, spontaneous cycle length. 'Significantly different from the control at P<0.05 (Student's t-test). 


\section{Discussion}

The present study shows that S-312, a new dihydrothienopyridine derivative, markedly relaxed the contractions of isolated rabbit arteries evoked by high $\mathrm{K}^{+}, 5-\mathrm{HT}$ and U46619. and inhibited $\mathrm{Ca}^{++}$-induced contraction in depolarized preparations. These actions are qualitatively similar to those of nifedipine and nicardipine.

In $\mathrm{K}^{+}$-depolarized femoral and basilar arteries, the inhibitory effect of S-312 on the $\mathrm{Ca}^{++}$-induced contraction was overcome by raising the $\mathrm{Ca}^{++}$concentration of the bathing solution, and a competitive antagonism was found. Such a calcium antagonistic effect on vascular smooth muscles of well-known calcium antagonists has been previously reported (24-26), and those effects with nifedipine and nicardipine were also reconfirmed in our experiments. S-312 caused dose-dependent relaxation in high $\mathrm{K}^{+}$-induced sustained contractions. Direct vasocontractions produced by $\mathrm{K}^{+}$-depolarization are mainly due to increased $\mathrm{Ca}^{++}$influx through the depolarized cell membrane $(27$. 28). In addition. S-312 inhibited specific [ $\left.{ }^{3} \mathrm{H}\right]$ - NTD binding in rat cerebral cortex membrane (9). NTD has been shown to block the voltage-dependent $\mathrm{Ca}^{++}$channel in vascular smooth muscle cells (29). Therefore, the calcium antagonistic and relaxant effects of S-312 in depolarized rabbit arteries observed in the present study would be due to a blockade of the transmembrane $\mathrm{Ca}^{++}$influx through the voltage-dependent $\mathrm{Ca}^{++}$channel. These effects of $\mathrm{S}-312$ on $\mathrm{K}^{+}$- and $\mathrm{Ca}^{++}$-induced contractions were much greater than those of nifedipine and were comparable to or slightly more potent than those of nicardipine. It is assumed, therefore, that the blocking potencies on the voltage-dependent $\mathrm{Ca}^{++}$channel in vascular smooth muscles are in the order of S-312 $\geqq$ nicardipine $>$ nifedipine. The present study also showed that the calcium antagonistic effect of $\mathrm{S}-312$ was more pronounced in the basilar artery than in the femoral artery.

Differing from the inhibitory effect of $S$ 312 in depolarized preparations, S-312 inhibited the NE-induced contraction only partially even at the highest concentration tested, and non-competitive antagonism was found. NE is considered to bring about vascular contractions both by increasing the transmembrane $\mathrm{Ca}^{++}$influx and by releasing $\mathrm{Ca}^{++}$from the intracellular binding site (28, $30)$. which can be triggered by inositol trisphosphate $(31,32)$. A low concentration of S-312 markedly inhibited the $\mathrm{Ca}^{++}$-induced contraction in NE-exposed femoral strips. However, NE-induced contraction in the $\mathrm{Ca}^{++}$-free condition was not affected. These results indicate that $S-312$ can block the NEoperated $\mathrm{Ca}^{++}$influx from extracellular fluid across the plasma membrane, not the release of intracellularly bound $\mathrm{Ca}^{++}$. These properties of S-312 could explain its partial inhibition of NE-contraction in normal solution. In addition. no effect of S-312 on the contraction evoked by $\mathrm{Ca}^{++}$in skinned fiber of isolated taenia caecum indicates that the calmodulin and contractile protein systems were not affected directly $S-312$.

5-HT and thromboxane $A_{2}$ have been suggested as possible mediators of cerebral and coronary vasospasms (33-35). S-312 inhibited the 5-HT-induced contraction of isolated rabbit basilar artery and the U46619induced contraction in the coronary artery more potently than nifedipine and nicardipine. Therefore S-312 may effectively prevent cerebral and coronary vasospasms caused by some circulatory disorders.

In high $\mathrm{K}^{+}$-depolarized femoral arteries, the duration of the vasodilating action of S-312. which was evaluated in the wash-out experiment, was longer than those of nifedipine and nicardipine. These results show that $S$ 312 is not easily removed from the voltagedependent $\mathrm{Ca}^{++}$channel by washing. This property might explain the long lasting increase by $S-312$ of coronary perfusion flow in the isolated guinea pig heart (9) and also supports its long lasting vasodilating effects in vivo as has been discussed by other investigators $(20,26)$

In isolated guinea pig atria, the negative inotropic effect of S-312 was observed at a higher concentration (above $3 \times 10^{-7} \mathrm{M}$ ), and this effect was considerably weaker compared with those of nifedipine and nicardipine. Also. high concentrations (above $3 \times 10^{-8}$ or $10^{-7}$ $\mathrm{M})$ of S-312 increased the $\mathrm{AH}$ interval of the 
His bundle electrogram in the Langendorffperfused isolated rabbit heart and depressed the $\dot{V}_{\max }$ and AMP of the action potential in isolated rabbit sinus node preparations. These electrophysiological effects on the myocardium should be mainly due to a blockade of transmembrane $\mathrm{Ca}^{++}$influx through the cardiac slow channel $(36,37)$. In the Langendorff-perfused isolated rabbit heart, SA and HV intervals were not affected by $S-312$. which indicates that $S-312$ does not block the fast sodium channels.

These studies thus show that $\mathrm{S}-312$ seems to have higher selectivity for vascular smooth muscles, especially for cerebrovascular smooth muscles, and this selectively is apparently greater than those of nifedipine and nicardipine. The precise explanation for such tissue and regional selectivity of drug action is not known, but this selectivity is interesting and has been studied by several investigators from the viewpoints of voltagedependency and others $(2,29,38)$.

Recently, several $\mathrm{Ca}^{++}$antagonists have been widely used for the treatment of many cardiovascular disorders (2). Marked prophylactic effects of S-312 on the occurrence of stroke and significant increase of life span in SHRSP were already reported by our group (39). The potent and vasculo-selective, especially to cerebral vessels, action of S-312. and its long-lasting action may be useful in the treatment of various cerebrovascular disorders.

Acknowledgments: We wish to express our sincere appreciation to Dr. M. Fujiwara (Professor, Department of Pharmacology, Faculty of Medicine. Kyoto University). Dr. J. Toyama, Professor, and Dr, I. Kodama (Department of Circulation and Respiration. The Research Institute of Environmental Medicine, Nagoya University) for their valuable discussions and helpful advice on the isolated cardiovascular preparations. We also acknowledge the helpful advice of Dr. T. Tasaki (Shionogi Research Laboratories) on data analyses.

\section{References}

1 Pepine, C.J., Feldman, R.L., Hill, J.A., Conti, C.R., Mehta, J., Hill, C. and Scott, E.: Clinical outcome after treatment of rest angina with calcium blockers: Comparative experience during the initial vear of therapy with diltiazem. nifedi- pine and verapamil. Am. Heart J. 106, 13411347 (1983)

2 Godfraind, T., Miller, R. and Wibo, M.: Calcium antagonism and calcium entry blockade. Pharmacol. Rev. 38, 321-416 (1986)

3 Sorkin, E.M. and Clissold, S.P.: Nicardipine: A review of its pharmacodynamic and pharmacokinetic properties, and therapeutic efficacy. in the treatment of angina pectoris, hypertension and related cardiovascular disorders. Drugs 33 , 296-345 (1987)

4 Takenaka, T.: Effect on the cerebral circulation of 2,6-dimethyl-4-(3-nitrophenyl)-1,4-dihydropyridine-3,5-dicarboxylic acid 3-2-(N-benzyl$\mathrm{N}$-methylamino)-ethyl ester 5-methyl ester hydrochloride (YC-93). Clin. Report 8, 51-64 (1974)

5 Towart, R. and Perzborn, E.: Nimodipine inhibits carbocyclic thromboxane-induced contractions of cerebral arteries. Eur. J. Pharmacol. 69, 213215 (1981)

6 White, R.P., Cunningham, M.P. and Robertson, J.T.: Effect of the calcium antagonist nimodipine on contractile responses of isolated canine basilar arteries induced by serotonin, prostaglandin $\mathrm{F}_{2 \alpha}$. thrombin, and whole blood. Neurosurgery 10 , 344-348 (1982)

7 Mannhold, R.: Nimodipine. Drugs of Today 21 , 536-539 (1985)

8 Gelmers, H.J.: Effect of calcium antagonists on the cerebral circulation. Am. J. Cardiol. 59, 173B-176E (1987)

9 Adachi, I., Yamamori, T., Hiramatsu, Y., Sakai, K., Mihara, S., Kawakami, M., Masui, M., Uno, 0. and Ueda, M.: Studies on dihydropyridines. IIl. Synthesis of 4.7-dihydrothieno[2,3-b]pyridines with vasodilator and antihypertensive activities. Chem. Pharm. Bull. (Tokyo) 36, 4389-4402 (1988)

10 Toda, N.: The action of vasodilating drugs on isolated basilar, coronary and mesenteric arteries of the dog. J. Pharmacol. Exp. Ther. 191, 139146 (1974)

11 Saida, K. and Nonomura, Y.: Characteristics of $\mathrm{Ca}^{2+}$ - and $\mathrm{Mg}^{2+}$-induced tension development in chemically skinned smooth muscle fibers. J. Gen. Physiol. 72, 1-14 (1978)

12 Wallenstein, S., Zucker, C.L. and Fleiss, J.L.: Some statistical methods useful in circulation research. Circ. Res. 47, 1-9 (1980)

13 Finney, D.J.: Statistical Method in Biological Assay (3rd edition). p. 69-104, p. 203-215. Charles Griffin, London (1978)

14 Arunlakshana, O. and Schild, H.O.: Some quantitative uses of drug antagonists. Br. J. 
Pharmacol. 14, 48-58 (1959)

15 Vølund, A.: Application of the four-parameter logistic model to bioassay: Comparison with slope ratio and parallel line models. Biometrics 34, 357-365 (1978)

16 Coleman, R.A., Humphrey, P.P.A., Kennedy, I., Levy, G.P. and Lumley, P.: Comparison of the actions of U-46619. a prostaglandin $\mathrm{H}_{2}$ analogue, with those of prostaglandin $\mathrm{H}_{2}$ and thromboxane $A_{2}$ on some isolated smooth muscle preparations. Br. J. Pharmacol. 73, 773$778(1981)$

17 Burke, S.E., Lefer, A.M., Nicolaou, K.C., Smith, G.M. and Smith, J.B.: Responsiveness of platelets and coronary arteries from different species to synthetic thromboxane and prostaglandin endoperoxide analogues. Br. J. Pharmacol. 78, 287292 (1983)

18 Julou, G. and Freslon, J.-L.: Effects of calcium entry blockers on $\mathrm{Ca}^{2+}$-induced contraction of depolarized and noradrenaline-exposed rat resistance vessels. Eur. J. Pharmacol. 129, 261-270 (1986)

19 Van Rossum, J.M.: Cumulative dose-response curves II. Techniques for the making of doseresponse curves in isolated organs and evaluation of drug parameters. Arch. Int. Pharmacodyn. Ther. 143, 299-330 (1963)

20 Furuta, T.: Prolonged inhibitory effects of nilvadipine (FR34253) following washout in isolated rabbit aorta and mesenteric artery. J. Cardiovasc. Pharmacol. 11, 134-138 (1988)

21 Levin, R.M. and Weiss, B.: Selective binding of antipsychotics and other psychoactive agents to the calcium-dependent activator of cyclic nucleotide phosphodiesterase. J. Pharmacol. Exp. Ther. 208, 454-459 (1979)

22 Spedding, M.: Direct inhibitory effects of some 'calcium-antagonists' and trifluoperazine on the contractile proteins in smooth muscle. Br. J. Pharmacol. 79, 225-231 (1983)

23 West, T.C.: Ultramicroelectrode recording from the cardiac pacemaker. J. Pharmacol. Exp. Ther. $115,283-290(1955)$

24 Eigenmann, R., Blaber, L., Nakamura, K., Thorens, S. and Haeusler, G.: Tiapamil, a new calcium antagonist 1. Demonstration of calcium antagonistic activity and related studies. Arzneimittelforschung 31, 1393-1401 (1981)

25 Aoki, K. and Asano, M.: Effects of Bay K 8644 and nifedipine on femoral arteries of spontaneously hypertensive rats. Br. J. Pharmacol. $88,221-230(1986)$

26 Kikkawa, K., Murata, S. and Nagao, T.: Calcium antagonistic and spasmolytic activities of a new 1,5-benzothiazepine derivative in isolated canine and monkey arteries. Arzneimittelforschung 38, $526-531$ (1988)

27 Van Breemen, C. and McNaughton, E.: The separation of cell membrane calcium transport from extracellular calcium exchange in vascular smooth muscle. Biochem. Biophys. Res. Commun. 39, 567-574 (1970)

28 Bolton, T.B.: Mechanisms of action of transmitters and other substances on smooth muscle. Physiol. Rev. 59, 606-718 (1979)

29 Bean, B.P., Sturek, M., Puga, A. and Hermsmeyer, $K$ : Calcium channels in muscle cells isolated from rat mesenteric arteries: Modulation by dihydropyridine drugs. Circ. Res. 59, 229-235 (1986)

30 Peiper, U., Griebel, L. and Wende, W.: Activation of vascular smooth muscle of rat aorta by noradrenaline and depolarization: Two different mechanisms. Pflügers Arch. 330, 74-89 (1971)

31 Berridge, M.J.: Inositol trisphosphate and diacylglycerol as second messengers. Biochem. J. 220, 345-360 (1984)

32 Somlyo, A.V., Bond, M., Somlyo, A.P. and Scarpa, A.: Inositol trisphosphate-induced calcium release and contraction in vascular smooth muscle. Proc. Natl. Acad. Sci. U.S.A. 82, 5231-5235 (1985)

33 Ellis, E.F., Oelz, O., Roberts, L.J., II, Payne, N.A., Sweetman, B.J., Nies, A.S. and Oates, J.A.: Coronary arterial smooth muscle contraction by a substance released from platelets: Evidence that it is thromboxane $A_{2}$. Science $193,1135-1137$ (1976)

34 Luchi, R.J., Chahine, R.A. and Raizner, A.E.: Coronary artery spasm. Ann. Int. Med. 91, 441 . 449 (1979)

35 Silverberg, G.D., Ross, G., Corbin, S.D. and New, W.: Time course of serotonin-induced vasoconstriction. Neurosurgery 4, 539-542 (1979)

36 Wit, A.L. and Granifield, P.F.: Effect of verapamil on the sinoatrial and atrioventricular nodes of the rabbit and the mechanism by which it arrests reentrant atrioventricular nodal tachycardia. Circ. Res. 35, 413--425 (1974)

37 Irisawa, H.: Comparative physiology of the cardiac pacemaker mechanism. Physiol. Rev. $58,461-498$ (1978)

38 Morel, N. and Godfraind, T.: Prolonged depolarization increases the pharmacological effect of dihydropyridines and their binding affinity for calcium channels of vascular smooth muscle. J. Pharmacol. Exp. Ther. 243, 711-715 (1987)

39 Masui, M., Hara, S., Ueda, M. and Ito, H.: Prophylactic effects of Ca blockers on the occurrence of stroke in SHRSP. Japan. Heart J. 29, 587 (1988) 